\title{
The intimate nature of oculomotor muscles contracture
}

\author{
A natureza íntima da contratura do músculo oculomotor
}

Carlos Ramos deSouza-Dias ${ }^{1}$

Work carried out at the Ophthalmology Department of Faculdade de Ciências Médicas da Santa Casa de São Paulo - São Paulo (SP) - Brazil.

${ }^{1}$ Professor Titular do Departamento de Oftalmologia da Faculdade de Ciências Médicas da Santa Casa de Misericórdia de São Paulo - São Paulo (SP) - Brazil.

Correspondence address: Carlos R. Souza-Dias. Rua Cincinato Braga, 59 - Cj. 5 - Bl. 2 São Paulo (SP)

CEP 01333-011

E-mail: csdias@uol.com.br

Recebido para publicação em 06.04.2009

Ultima versão recebida em 02.12.2009

Aprovação em 17.12.2009

Nota Editorial: Depois de concluída a análise do artigo sob sigilo editorial e com a anuência do Dr. Marcelo Francisco Gaal Vadas sobre a divulgação de seu nome como revisor, agradecemos sua participação neste processo.

\begin{tabular}{|l|}
\hline ABSTRACT \\
\hline The author makes comments about the shortening and loss of elasticity \\
of the oculomotor muscle that remains slack for some time (contracture), \\
by means of a reasoning based on the Hooke's law and on the papers \\
carried out to demonstrate that a muscle that remains relaxed for some time \\
suffers a shortening due to loss of sarcomeres on the longitudinal direction \\
and the increase of the cross-sectional area due to the increase of collagen \\
tissue in the perimysium and the endomysium.
\end{tabular}

Keywords: Muscle contraction; Muscles/anatomy \& histology; Contracture/physiopathology; Ocular physiological processes; Oculomotor muscles/physiology; Eye movements; Sarcomeres/physiology; Adaptation physiological

\section{INTRODUCTION}

It is well known that an oculomotor muscle that remains slack during a certain time, for lack of opponent force caused by paralysis of its antagonist, by slipping during or just after surgery or by excessive recession, suffers a process named contracture, manifested by reduction of elasticity and length. This is an important phenomenon, because it impairs the achievement of postoperative comitance. The intrinsic and mechanical nature of the reduction of elasticity and length, which is felt in the forced duction test, deserves some comments.

Jampolsky stated ${ }^{(1)}$, in a paper that I consider one of the milestones in the evolution of the modern thought in strabismology, that an oculomotor restriction caused by muscle contracture may be felt in the forced duction test as a less abrupt or more abrupt tether; in the first case, it starts to be perceived gradually, increasing its intensity as the passive movement progresses. He coined this kind of restriction cushioned. The more representative example of this situation is the incipient medial rectus muscle contracture in not very ancient cases of lateral rectus paralysis; the eye can be driven into full abduction with the forceps, but one feels in the fingers that it requires more-than-normal force. We call it relative restriction ${ }^{(2)}$. In the second case, the eye can be driven up to a certain point with normal force, but suddenly a strong restriction impedes further movement, as if the eye collided against a hard obstacle; this is, for instance, what happens in the Brown's syndrome, in which the passive elevation in adduction is free up to a certain point, when it becomes abruptly restricted. We call it absolute restriction $^{(2)}$. A mixed restriction ${ }^{(2)}$ may also exist, as in longstanding lateral rectus paralysis: a more-than-normal force is required to move the eye with the forceps (as in relative restriction) up to a certain 
point, when a strong restriction suddenly impedes continuation of the movement (as in absolute restriction). The elongation-force curves show these three situations (these curves are generally called length-tension curves, but we prefer to call them elongation-force curves, for one does not register length but elongation and does not register tension but force [tension is force divided by cross-sectional area]) (Figure 1).

Castanera de Molina ${ }^{(3)}$, studying elongation-force curves of patients with different types of strabismus, observed the existence of four different patterns of inclination: of normal, stiff, tight, and slack muscle. These curves reflect different degrees of muscle elasticity.

Based on these studies, one can suppose that the contracture is caused by a structural change of the muscle that results in reduction of its elasticity, making it stiffer.

Williams, Goldspink ${ }^{(4)}$, Goldspink, Williams ${ }^{(5)}$, Tabary et al. ${ }^{(6)}$ and $\operatorname{Scott}^{(7)}$ demonstrated histologically a reduction of the number of sarcomeres, in the longitudinal direction, in the muscles that remains loose during some time; Williams, Goldspink $^{(4)}$ and Goldspink, Williams ${ }^{(5)}$ studied the phenomenon in limb muscles, whereas Scott studied oculomotor muscles. Tabary et al., studied it in the soleus muscle of cats $^{(6)}$. Goldspink, Williams ${ }^{(5)}$ showed that "In muscles immobilized in the shorten position, sarcomeres are lost and the remaining sarcomeres are altered to a length that enables the muscle to develop its maximum tension at the length which corresponds to the immobilized position. In muscles immobilized in the lengthened position, sarcomeres are added on and this fact results in sarcomere length being reduced as compared with non adapted muscle fixed in a similar position". These authors also showed that the new sarcomeres are added on at the ends of the existing myofibrils.

We made experiences on the elasticity of rubber bands and steel spring models by means of elongation-force curves.

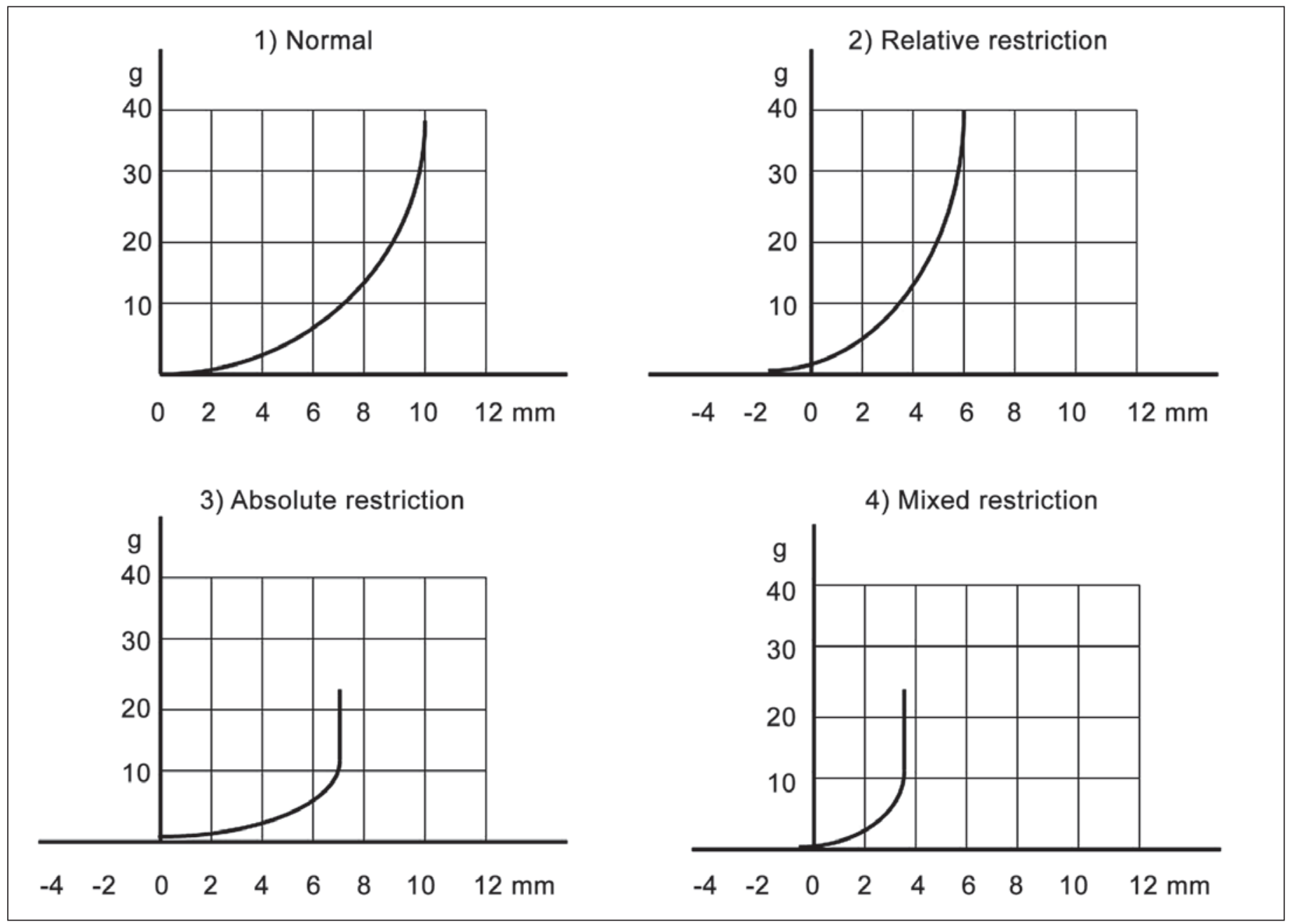

Figure 1 - Schematic drawing of 4 types of elongation-force curves according to the muscle stiffness: 1) Curve of a normal duction; a muscle elongation of $10 \mathrm{~mm}$ (full duction $=50^{\perp}$ ) requires a force of $\left.40 \mathrm{~g} ; 2\right)$ Curve of a relative restriction; a force of $40 \mathrm{~g}$ elongates the muscle $6 \mathrm{~mm}\left(30^{\perp}\right.$ duction); the curve is steeper; 3 ) Curve of an absolute restriction; a force of $10 \mathrm{~g}$ elongates the muscle $6.5 \mathrm{~mm}$ (about $35^{\Delta}$ duction) but then the trace becomes vertical, i.e., the increase of force is not able to elongate it further; 4) Curve of a mixed restriction; a force of $10 \mathrm{~g}$ elongates the muscle $3.5 \mathrm{~mm}$ (about 18 $8^{\Delta}$ duction - relative restriction) and then the trace becomes vertical, which means that the increase of force is not able to drive the eye further (absolute restriction) 
All the materials produced similar curves, but with different shapes from the oculomotor muscles. Considering the hypotheses that the curves were different because of their larger lengths. We shortened them gradually, which resulted in steeper curves but with unchanged shape. We concluded that those models were inadequate, probably because of the structural differences between them and the extraocular muscles.

The materials in general can be divided into two types, according to their behavior under the action of a deforming force: the plastic and the elastic materials. The plastic ones, under the action of a force, deform themselves and, once ceased the deforming force, they remain deformed, as the clay; the energy applied in its deformation is dissipated in the form of heat. The elastic materials, under the same force, deform themselves but, ceased the force, they restore their primitive form, as the office's rubber band; the energy applied for its deformation is stored and then restored under the form of movement. The materials found in the nature are generally mixed, that is, under the action of a force, they deform themselves and, ceased the force, they restore incompletely the primitive form, remaining some definitive deformation. So they have plastic and elastic features. This phenomenon can be seen when one does a complete passive duction in the eye of an anesthetized patient and then releases it; the eye returns incompletely to its original position. The distance between the original and the new position represents the plastic deformation, which Jampolsky proposes to eliminate making to-and-fro movements in the "spring-back balance force test"(8). A material may be perfectly elastic up to a certain limit of applied force, becoming permanently deformed when the force is increased, until they break when they reach their maximum tension.

The elasticity of the materials follows the Hooke's law (Robert Hooke, astronomer, mathematician, formulated the law of the materials' resistance - 1635-1703, London), expressed by the formula $\mathrm{F}=\mathrm{Y}$. E. A/L, in which $\mathrm{F}$ is the applied force, $\mathrm{A}$ is the cross-sectional area (of a bar), $\mathrm{Y}$ is the Young's module, $\mathrm{E}$ is the elongation of the material under the force $\mathrm{F}$ and $\mathrm{L}$ is its original length. (The Young's module is a characteristic of each material, defined as Y= FL/AE) (Thomas Young, physician, philologist and Egyptologist, discovered the accommodation of the crystalline lens - 1773-1829, London). The constant of elasticity (k), also dependent on the material of which the piece is made, depends also on the piece's length and of its cross-sectional area; it is known as Hooke's constant.

The Hook's formula is the equation of a straight line. In a graphic, if one plots applied forces on the ordinate and elongation on the abscissa, one obtains a straight line. Its inclination is defined by the formula $\operatorname{tg} \beta=\mathrm{k}=\mathrm{Y}$. A/L, i.e., the larger the cross-sectional area and/or the Young's module, the steeper the line (which means that the elongation is smaller) and the larger the original length, the less steep the line (the elongation is larger); one can express it also as the larger the constant of elasticity (k), the less elastic the piece (Figure 2). The opposite of $\mathrm{k}$ is $\mathrm{r}$, the coefficient of rigidity.

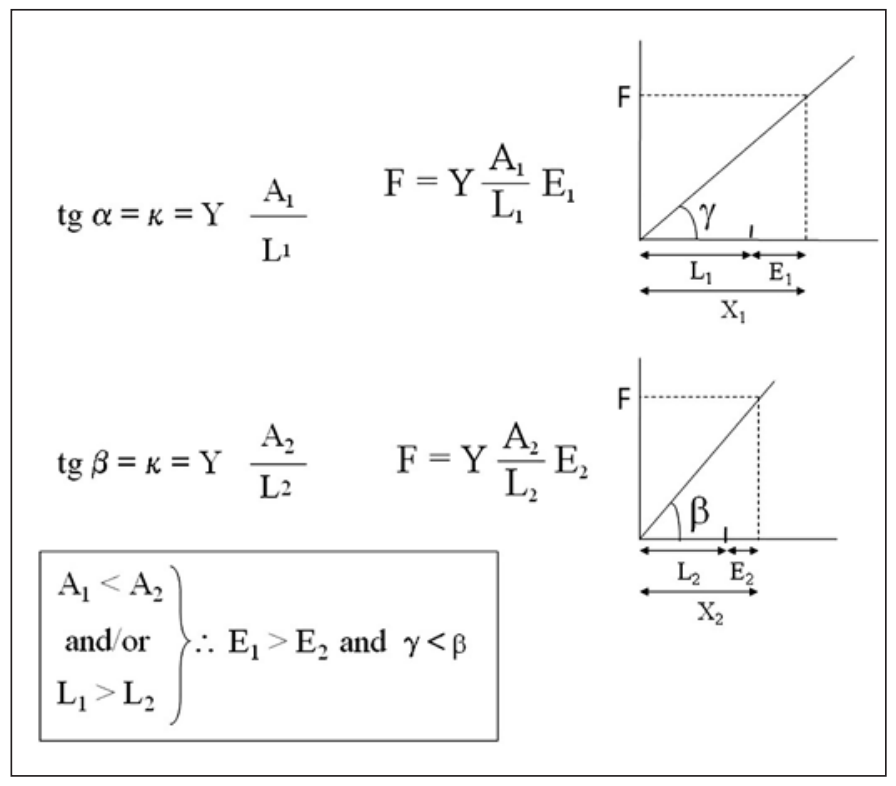

Figure 2 - Elongation of two pieces of the same elastic material (same $Y$ ) under the action of the same force $(F)$. The area of the cross section of the piece $2\left(A_{2}\right)$ is larger than the one of the piece $1\left(A_{1}\right)$ and the length of the piece $1\left(L_{1}\right)$ is larger than the one of piece $2\left(L_{2}\right)$; consequently, the elongation of material $1\left(E_{1}\right)$ is larger than the one of material $2\left(E_{2}\right)$ and the curve 2 is steeper than the curve $1(\gamma<\beta)$.

But, as we have seen in the figure 1, the graphic of the oculomotor muscles' elongation-force is not a straight line, but an exponential curve. A possible explanation for that (considering the muscle as a bar) is the fact that the structure of the muscle is complex; it has in its constitution muscular fibers, collagen (endomysium, perimysium, epimysium) etc. Furthermore, there are different muscle fibers into the muscle (fast and slow fibers). Each one of these components may have its own Young's module, as well as its limit of elasticity. The muscle's elongation-force curve would be a combination of partial curves. This fact indicates that the Young's module, in the case of the oculomotor muscles, is not constant, that is, for each unity of the deformation force increment, the module also increases. The increment of force necessary to elongate the muscle from 4 to $6 \mathrm{~mm}$ is smaller than the increment of force necessary to elongate it from 6 to $8 \mathrm{~mm}$. This means that $\mathrm{Y}$ is an exponential function; in order to follow this reasoning, let us consider that $\mathrm{Y}=\alpha \mathrm{E}$ (in which $\mathrm{E}=$ elongation), which leads to $\mathrm{E}^{2}=\mathrm{FL} / \alpha \mathrm{A}$ (Figure 3).

$\mathrm{Scott}^{(7)}$ demonstrated that the oculomotor muscle that remains slack for some time looses sarcomeres, becoming definitively shorter. If one applies the Hooke's formula to this muscle, it is valid to think that the angle of inclination of its elongation-force curve becomes larger (the curve becomes steeper) (Figure 2). This fact could explain by itself the increase of the muscle rigidity (the reduction of its elasticity) that is observed in the forced duction test. But Scott did not study the cross-sectional area. Williams, Goldspink, in $1984^{(9)}$, demonstrated that "...during immobilization in the shortened position there is an increase in the proportion of collagen to muscle 


$$
\begin{aligned}
& \mathrm{F}=\mathrm{Y} \frac{\mathrm{A}}{\mathrm{L}} \mathrm{E} \quad \text { (Hooke's formula) } \\
& \mathrm{Y}=\alpha \mathrm{E} \quad \mathrm{Y}=\mathrm{FL} / \mathrm{AE} \text { (see text) } \\
& \mathrm{F}=\alpha \mathrm{E} \frac{\mathrm{A}}{\mathrm{L}} \mathrm{E} \\
& \mathrm{F}=\alpha \frac{\mathrm{A}}{\mathrm{L}} \mathrm{E}^{2} \\
& \mathrm{E}^{2}=\frac{\mathrm{FL}}{\alpha \mathrm{A}}
\end{aligned}
$$

Figure 3 - Mathematical reasoning that leads to $E^{2}=F L / \alpha A$, which means that the increase of the deformation force or the original length, or the reduction of the cross section leads to the square of the elongation

fiber tissue". They also stated that "Following immobilization of a muscle in its shortened position, the proportion of both endomysium and perimysium is increased". These facts cause an increase of the muscle stiffness, because of the smaller elasticity of the collagen (greater Young's module) and the increase of the cross-sectional area (A). Scott had already made reference to this fact in $1971^{(10)}$. The increase of the amount of collagen probably leads to the increase of the cross-sectional area (A), causing an increase of the curve's steepness (Figure 4). There are not, in the best of our knowledge, studies about the number of sarcomeres in the cross-sectional area of the contractured muscle: would it also increase?

Applying that reasoning to the different patterns of the forced duction test, one can suppose:

1) Increase of the contents of collagen in the muscle may reduce the limit of elongation of the contractured muscle, impeding the muscular fibers to be stretched to their limit. After a certain point, but before attaining the full duction, the elongation-force curve becomes vertical, showing that the limit of muscle elongation is attained; one feels in the fingers the impossibility of driving the eye further. This explains the abrupt restriction (absolute restriction).

2) Probably, in the normal muscle the limit of passive duction is shorter than the limit of its elasticity. The maximal duction amplitude may be determined by the limit of elongation of the periocular sheaths and the check ligaments. If it is so, the muscle can be shortened up to a certain point without reducing the duction amplitude. But, according to the Hooke's formula, this muscle shortening (smaller L) increases its stiffness (or reduces its elasticity), i.e., it makes the curve steeper. This fact could explain the relative restriction (Jampolsky's cushioned restriction), i.e., the restriction in which the duction limit is preserved but the forced traction test demands a morethan-normal force in order to attain the full rotation. Besides the shortening, the increase of the cross sectional area (A) would act in the same sense, adding their effects.

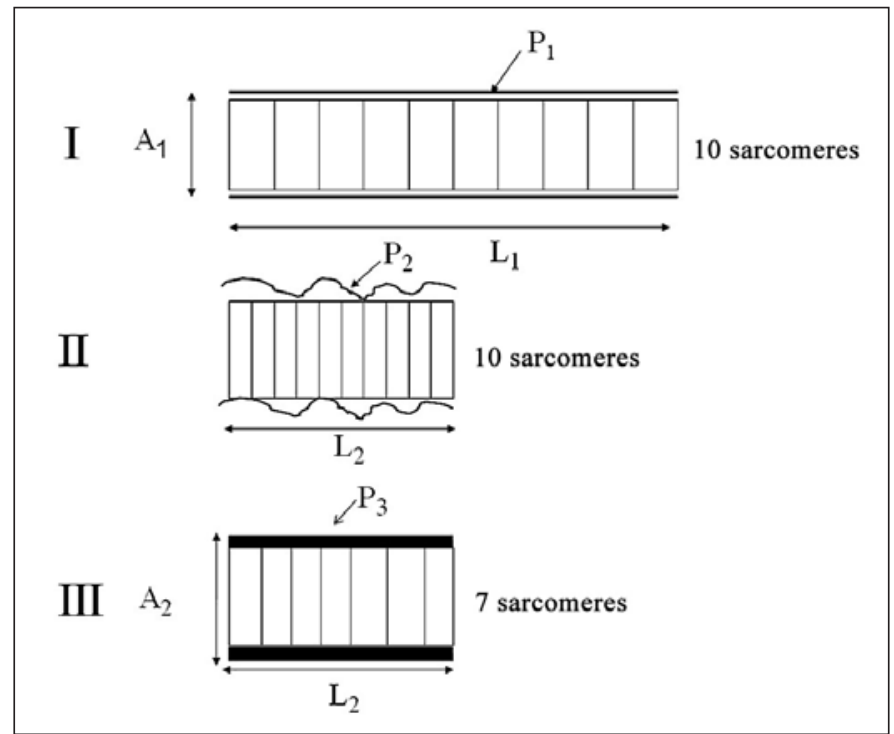

Figure 4 - (I) A normal relaxed muscle fiber, with 10 sarcomeres in the longitudinal arrangement; (II) The same muscle fiber in contracted state, with the same number of sarcomeres (10); (III) The same muscle fiber some time later (muscle contractured); the number of sarcomeres is reduced (7) and there is a thickening of the perimysium and endomysium because of the increase of their collagenous tissue components. $P_{1}=$ normal perymisium and endomysium; $A_{1}=$ crosssectional area of the normal muscle fiber; $L_{1}=$ length of the normal muscle fiber; $P_{2}=$ loose perimysium and epimysium; $P_{3}=$ thickened epimysium and perimysium; $A_{2}=$ enlarged area of the cross section of the shortened muscle fiber; $\mathrm{L}_{2}=$ length of the contracted and the shortened muscle fiber

The above reasoning shows that the difference between the relative and absolute restrictions caused by muscle contracture is a question of degree (except in cases of extra muscular restrictions, as scleral adherences).

The definitive elucidation of these questions demands deeper studies. It is intriguing the Collins et al., statement ${ }^{(11)}$ that the shape of the elongation-force curve of the contractured muscle is similar to the one of the normal muscle curve (except in Duane's syndrome), which is in disagreement with what one feels in the fingers in the forced duction test and with the Hooke's law. It is something that must be elucidated.

\section{RESUMO}

O autor procura demonstrar a razão da perda de elasticidade e do encurtamento do músculo oculomotor que permanece relaxado durante certo tempo (contratura), mediante raciocínio baseado na lei de Hooke e nos trabalhos que demonstram que o músculo oculomotor que permanece frouxo por algum tempo sofre encurtamento devido à perda de sarcômeros no sentido longitudinal e ao aumento da área da secção transversa, devida ao aumento do tecido colágeno do perimísio e do endomísio.

Descritores: Contração muscular; Músculos/anatomia \& histologia; Contratura/fisiopatologia; Processos fisiológicos 
oculares; Músculos oculomotores/fisiologia; Movimentos oculares; Sarcômeros/fisiologia; Adaptação fisiológica

\section{REFERENCES}

1. Jampolsky A. Surgical leashes and reverse leashes in strabismus management In: Symposium on Strabismus. Transactions of the New Orleans Academy of Ophthalmology; 1978. St. Louis: C.V. Mosby. p.244-68.

2. Prieto-Díaz J, Souza-Dias C. Estrabismo. $5^{\underline{a}}$ ed. Buenos Aires, Argentina: Ediciones Científicas; 2005; p.75.

3. Castanera de Molina A. EOM mechanical adaptation in strabismus patients. In: Mechanics on Strabismus Symposium; 1991 Oct 18-19. Proceeding. San Francisco: The Smith-Kettlewell Eye Research Institute. p.55-67.

4. Williams PE, Goldspink G. Longitudinal growth of striated muscle fibers. J Cell Sci. 1971;9(3):751-67.

5. Goldspink G, Williams P. Cellular mechanisms involved in the determination of muscle length and mass during growth; problems arising from imbalance between antagonists muscle groups. In: Mechanics on Strabismus Symposium; 1991 Oct 18-19. Proceeding. San Francisco: The Smith-Kettlewell Eye Research Institute. p.195-206.

6. Tabary JC, Tabary C, Tardieu C, Tardieu G, Goldspink G. Physiological and structural changes in the cat's soleus muscle due to immobilization at different lengths by plaster cats. J Physiol. 1972;224(1):23-44.

7. Scott AB. Change in eye muscle sarcomeres according to eye position. J Pediatr Ophthalmol Strabismus. 1994;31(2):85-8.

8. Jampolsky A. Spring-Back-Balance test in strabismus surgery. In: Symposium on Strabismus. Transactions of the New Orleans Academy of Ophthalmology; 1978. St. Louis: C.V. Mosby. p.111.

9. Williams PE, Goldspink G. Connective tissue changes in immobilized muscle. J Anat. 1984;138(Pt 2):343-50.

10. Scott AB. Extraocular muscle forces in strabismus. In: Bach-y-Rita P, Collins CC, Hyde JE, editors. The control of eye movements. London: Academic Press; 1971. p.327-42.

11. Collins CC, Jampolsky A, Howe PS. Mechanical limitations of rotation. In: Mechanics on Strabismus Symposium; 1991 Oct 18-19. Proceeding. San Francisco: The Smith-Kettlewell Eye Research Institute. p.244-68. 